\title{
312 Features of Stir Zone Structure Resulted from Friction Stir Welding of a ZK60 Magnesium Alloy
}

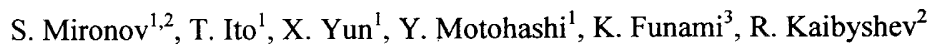 \\ ${ }^{1}$ Research Center for Superplasticity, Faculty of Engineering, Ibaraki University, Hitachi, Ibaraki 316-8511, \\ Japan \\ ${ }^{2}$ Institute for Metals Superplasticity Problems, Khalturina 39, Ufa 450001, Russia \\ ${ }^{3}$ Department of Mechanical Engineering, Chibo Institute of Technology, Chibo, Japan
}

Structure resulted from Friction Stir Welding (FSW) of a ZK60 magnesium alloy have been investigated. Structural heterogeneity has been revealed. The FSW-induced features of the structure have been analysed. It was shown that temperature, strain, and stress would vary in the stir zone. The correlation between the structure heterogeneity and specific character of plastic flow during FSW has been discussed.

\section{INTRODUCTION}

Friction Stir Welding (FSW) is a new method of welding. The feature of the method - is a "solid state» welding (without melting) via severe plastic deformation (1). FSW has a lot of advantages in comparison with another methods of welding. The joining in the solid state allows avoiding oxidation, contamination, and porosity inside of weld. As a result, FSW can be used for joining «unweldable» materials such as aluminium and magnesium alloys. It makes this technique very perspective for aerospace and automotive industries.

Investigation of structures evolved inside the Stir Zone (SZ) is one of the important topics in the study of FSW process. Many investigations of this kind have been focused on microstructures. As it follows from them, microstructure evolution during FSW could be regarded as recrystallization (2-6). However, in spite of the importance of all these results, they have not reflected fully complexity and peculiarity of plastic flow during FSW. In Ref. (7) special experiment was carried out for detailed investigation of this process. Two different aluminium alloys were FSWed and their different response to etching allows visualizing the process. It suggested that plastic flow was very complex and heterogeneous. The large (macro-scale) parts of material were dislocated and mixed as a whole and welds were characterized by a «multi-layer» structure («flow patterns») as a result. Transfer of material from RS to AS (or vice versa) was dominated. In the transversal section of the weld the corresponding layers seemed as concentrated circles or ellipses of macro-scale sizes; they were designated as "onion rings» in Ref. (8).

Thus it is suggested that structure evolved in SZ during FSW is rather specific. Investigation of microstructure only is not enough because more scaled features of structure take place ( (flow patterns»). Hence, the multi-scale analysis of SZ structure is required. In this connection, the object of the present study is to make macro-scale analysis of SZ structure resulted from FSW.

\section{EXPERIMENTAL PROCEDURE}

The material tested was an extruded ZK60 magnesium alloy. The standard chemical composition is $\mathrm{Zn} \mathrm{4.8-6.2,} \mathrm{Zr} \mathrm{0.5-0.8,} \mathrm{Cu}$ $\leq 0.03, \mathrm{Ni} \leq 0.005$ and balance $\mathrm{Mg}$ (all in mass \%).

Two strips with dimensions $125 \times 50 \times 3 \mathrm{~mm}$ were cut from the alloy. One side surface of the strips $(125 \times 3 \mathrm{~mm})$ was mechanically polished and then butt-FSWed together with the single pass only. The welding tool was made from carbon tool steel SKH 9. The tool has a $14 \mathrm{~mm}$ diameter shoulder part and a M6 pin. The pin length was $2.8 \mathrm{~mm}$. The tool was tilted by $3^{\circ}$ from the strip normal, such that the rear of the tool was lower than the front and had a shoulder plunge depth of $0.1 \mathrm{~mm}$ below the strip surface. The pin rotation speed was $600 \mathrm{rpm}$ and the pin travelling speed was $100 \mathrm{~mm} / \mathrm{min}$. Temperature during FSW was measured at the centre of the strip thickness with three thermocouples (at the points of the welding start, end and middle).
Temperature was about $450^{\circ} \mathrm{C}$ (about $0,8 \mathrm{~T}_{\mathrm{m}}$ ) at the moment the tool was just passing in all cases. Air-cooling was applied after FSW.

Sample for structural observations was cut perpendicularly to the tool travelling direction in the centre of weld line. It was mechanically ground with water abrasive paper, bath-polished with $1 \mu \mathrm{m}$ diamond and chemically etched in a solution of $4.2 \mathrm{~g}$ picric acid $+65.8 \mathrm{ml}$ ethanol $+10 \mathrm{ml}$ acetic acid $+10 \mathrm{ml}$ distilled water within 7-10 s. After etching sample was washed sequentially in ethanol and methanol jet.

\section{RESULTS}

Macro-scale structure of SZ transversal section is presented in Fig. 1. Three zones could be distinguished clearly. They are designated as Top Zone, Centre, and Nugget Zone in the figure. The first one was a near-surface zone with depth about one millimetre. Its shape could be described roughly as a trapezium and the bigger base of the one corresponds to the surface of the sample. It is seen that trapezium is asymmetrical and converges in RS direction. Zone Centre was located approximately in the centre of SZ. It was a tear-shaped and expanded in AS direction. Nugget Zone had an approximately elliptical shape and was asymmetrical also: its radius in AS side was smaller than in RS one. It should be noted that transversal size (width) of Nugget Zone was about six millimetres (Fig. 1); i.e. it was approximately equal to the pin diameter. Top Zone was separated from Centre and Nugget Zone by the clear bound; this region will be referred in the text as Bound (it did not designated in Fig. 1).

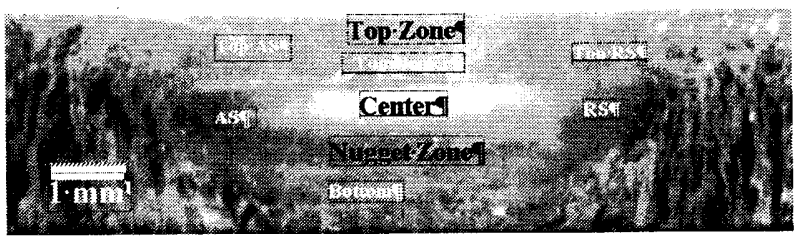

Fig. 1. Macro-scale structure inside of Stir Zone

\section{DISCUSSION}

During our experiment the welding tool shoulder was inserted in material to be welded. Hence, deformation was resulted not from rotating pin only but from rotating shoulder also. Features of loading conditions during FSW will be discussed below, however it could be noted a priori that torsion was an important component of the one (6). Since the diameter of the shoulder was greater the torsion strain and the torsion strain rate resulted from it were higher. Moreover, greater mass of the shoulder should be provided greater friction force and, as a consequence, higher temperature of heating in near-surface zone of a sample. To summarize of all above-mentioned it could be supposed that temperature, strain and strain rate decreased from top to dawn from shoulder to pin during our experiment. 
Let us analyse the loading conditions during FSW in detail (Fig. 2). Movement trajectory of a tool (pin and shoulder) is resulted from simultaneous rotation and translation motions. As a result, as it is shown in Fig. 2a, the first half of revolution from $0^{\circ}$ to $180^{\circ}$ transfers point $A$ to point $B^{*}$, but not to point $B$. In other words, material before too in point $B^{*}$ is compressed with respect to the one in point $B$. Compression degree is equal to the translation distance of a tool for a half of its revolution. According to the reference (8) this value could be calculated as:

$$
L=\frac{V}{2 N},
$$

where $V$ - tool translation speed and $N$ - tool rotation speed. Therefore, during rotation of tool from AS to RS (actually, during formation of structure in RS region) material is subjected to simultaneous torsion and compression. Analogously, the second half of revolution of a tool from $180^{\circ}$ to $360^{\circ}$ transfers point $B$ to point $A^{*}$, but not to point $A$. The material behind the too in point $\mathrm{A}^{*}$ is tensioned on the $L$ value with respect to the one in point A. Hence, during rotation of tool from RS to AS (actually, during formation of structure in AS region) material is subjected to simultaneous torsion and tension. In the similar way it is possible to show that material in central part of SZ is subjected, at first, to simultaneous torsion and compression and then simultaneous torsion and tension. The differences in the loading conditions imply the differences in the tensors of strain, strain rate and stress. Thus they must varied continuously across $\mathrm{SZ}$ - from RS to AS.

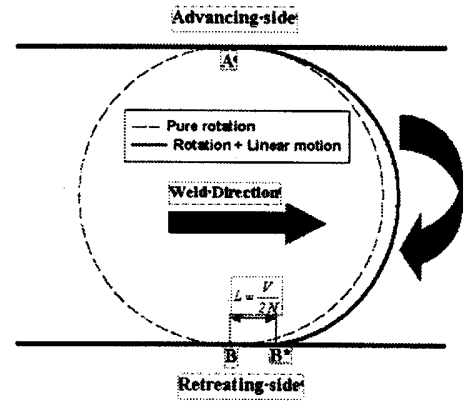

a

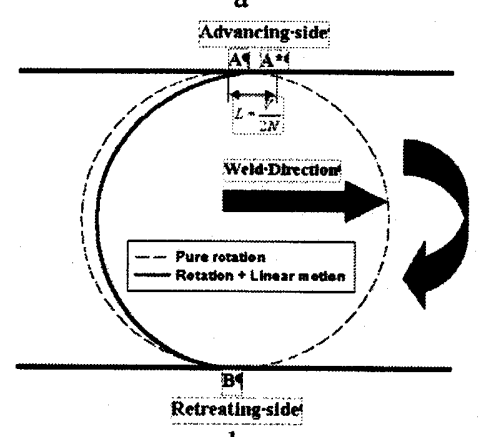

b

Fig. 2. Top view of a tool movement trajectory: $a$ - the first half of revolution from $0^{\circ}$ to $180^{\circ}, \mathrm{b}-$ the second half of revolution from $180^{\circ}$ to $360^{\circ}$

Let us analyse the possible temperature variation across SZ. Since it increasing is resulted from friction between a tool and material it is appropriate to suggest that sector behind the tool (already welded) must be hotter than before the one. Taking into account Fig. 2 it is means that during formation of structure in RS region tool pass through colder sector (not welded yet sector) in comparison with AS region. In other words, it is possible that there is a tendency of deformation temperature increasing from RS to AS.
Thus, as it follows from above mentioned analysis, the macroscale conditions of plastic flow (temperature, strain, strain rate and stress) should be varied in a complicated way inside of stir zone. However, probably the real situation was more complex due to tool tilting and a threaded pin.

The difference of macro-scale conditions of deformation explains in principle the macro-scale structure heterogeneity (Fig. 1). Let us to note some features. Very probably that formation of structure in a near-surface zone (Top Zone) was resulted from shoulder action and in Nugget Zone - from pin action. However, a shoulder plunge depth was $0.1 \mathrm{~mm}$ in our experiment but the depth of Top zone was about $1 \mathrm{~mm}$ (Fig. 1). Hence, it could be suggested that formation structure in the last one was resulted not from the immediate transfer of material due shoulder rotation but rather from the accommodation between different deformation of shoulder and pin per revolution. Taking into account difference in shoulder and pin diameters, it is possible to suppose that shape material transferred per every tool revolution was a funnel in three-dimensional space. The conical part of the one corresponded to Top Zone, the cylindrical - Nugget Zone and area of their intersection was Bound (Fig. 1). Origin of zone Centre is not clear fully. However, since it was located between Top Zone and Nugget Zone it could be supposed that formation of structure in the Centre was resulted from combined action of the shoulder and the pin.

\section{CONCLUSIONS}

1) Heterogeneity of structure has been revealed in the FSWed $\mathrm{Mg}$ alloy. Macro-scale structure was represented with three zones that distinguished clearly by optical contrast (Top Zone, Nugget Zone and Centre).

2) The specific character of FSW treatment must result in heterogeneity of plastic flow conditions in the SZ. The difference in diameters and masses of a shoulder and a pin and peculiarity of the tool movement trajectory must lead to variation of temperature, strain, strain rate and stress in macro-scale.

3) The heterogeneous nature of structure in the SZ is a result of specific character of FSW treatment. Features of a macro-scale structure were caused by the macro-scale heterogeneity of plastic flow.

\section{REFERENCES}

(1) Thomas, W.M. «Friction stir butt welding», Int. Patent No PCT/GB92/02203 (1991), and US Patent No. 5, 460, 317 (1995). (2) Sato, Y.S., Urata, M., Kokawa, H., Ikeda, K., Hall-Petch relationship in friction stir welds of equal channel angularpressed alloys, Mat. Sci. and Eng. A354 (2003), 298-305.

(3) Peel, M., Steuwer, A., Preuss, M., Withers, P.J., Microstructure, mechanical properties and residual stresses as a function of welding speed in aluminium AA5083 friction stir welds, Acta Mat., 51 (2003), 4791-4801.

(4) Hassan, Kh. A.A., Norman, A.F., Price, D.A., Prangnell, P.B., Stability of nugget zone grain structure in high strength Al-alloy friction stir welds during solution treatment, Acta Mat., 51 (2003), 1923-1936.

(5) Su, J.-Q., Nelson, T.W., Mishra, R., Mahoney, M., Microstructural investigation of friction stir welded 7050-T651 aluminium, Acta Mat., 51 (2003), 713-729.

(6) Chang, C.I., Lee, C.J., Huang, J.C., Relationship between grain size and Zener-Holllomon parameter during friction stir processing in AZ31Mg alloys, Scripta Mat., 51 (2004), 509-514.

(7) Li, Y., Murr, L.E., McClure, J.C., Flow visualization and residial microstructures associated with the friction-stir welding of 2024 aluminum to 6061 aluminum, Mat. Sci. and Eng., A271 (1999), 213-223.

(8) Krishnan, K.N., On the formation of onion rings in friction stir welds, Mat. Sci. and Eng., A327 (2002), 246-251. 